\title{
IMPACT OF PROCESSING PARAMETERS ON SURFACE ROUGHNESS AND STRAIN HARDENING OF TWO-PHASE STAINLESS STEEL
}

\author{
Tomasz Cyryl Dyl, Adam Charchalis \\ Gdynia Maritime University \\ Faculty of Marine Engineering, Department of Marine Maintenance \\ Morska Street 81-87, 81-225 Gdynia, Poland \\ tel.: +48585586 323, fax: +48585586399 \\ e-mail:t.dyl@wm.umg.edu.pl \\ Grzegorz Stradomski, Dariusz Rydz \\ Czestochowa University of Technology \\ Faculty of Production Engineering and Materials Technology \\ Armii Krajowej 19, 42-200 Czestochowa, Poland
}

\begin{abstract}
Products used in the construction of machines and shipbuilding as well as petrochemical industry, such as shafts, bars, pipes and the like from two-phase stainless steel are currently very popular. It is required that they meet certain quality criteria. They must be characterized by suitable properties of the surface layer to meet the requirements of potential buyers.

In the article impact of processing parameters on the degree of relative strain hardening and index of surface roughness reduction were presented. The burnishing process was carried out for two-phase stainless steel. Burnishing process of the shafts neck was performed using burnisher roller. The experimental research were obtained in the surface layer increase in hardness and the material ratio curve a convex shaped, which, taking into account the load capacity of the surface will be directly affected by its resistance to wear and corrosion. The experimental research by application of the burnishing process was made in the Laboratory of Production Engineering. After the studies it was found that the hardness of the surface layer and the roughness of the shaft necks an important influenced by technological parameters of processing (burnishing speed, feed rate and depth of burnishing). The objective of applying burnishing process may be, for example, the need to increase surface smoothness and dimensional accuracy of part.
\end{abstract}

Keywords: burnishing process, index of surface roughness reduction, degree of relative strain hardening, two-phase stainless steel

\section{Introduction to the object of burnishing process}

The object of burnishing process may be, for example, the need to increase surface smoothness and dimensional accuracy of part [1-10], as well as economic regards, the increase resistance to fatigue and corrosion resistance [8, 11-13]. The depth of plastic deformation and the value of hardening and machining accuracy are the main differences in machining results for each burnishing method. The burnishing process include: strengthening treatment - for which it is important to achieve the desired changes in the physical properties of the material, which among other reduce abrasive wear and increase hardness and fatigue strength; smoothing - which aims at reducing the roughness and roughness of the surface. Dimensional smoothing treatment - through which accurate dimensional accuracy is achieved, combined with obtaining of low surface roughness $[14,15]$. During planning of technological process of manufacturing or regenerating machine components, the method of burnishing, the machining conditions, the shape and number 
of burners should be selected. The choice of static pressure conditions during burnishing process is dependent on how the pressure components are applied to the workpiece surface, which can be elastic or rigid. The reliability of working machine and equipment is very important in the engineering, power, metallurgical or marine industries. For example, on a ship during a cruise, are made repairs of individual components of the ship's machinery. Often are regenerated external cylindrical surfaces (e.g. shaft seals of seawater pumps), for this purpose can be proposed burnishing rolling - pressuring process (BRP) can be proposed as a finishing treatment, which enables to obtain the technological quality requirements of the products surface layer.

The selection of burnishing conditions is based on approximate calculations of forces and unitary pressures, experimental results of materials with similar properties, universal nomograms, and specialist norms $[3,7,8,10,15]$. For cases where there are insufficient certain dependencies and nomograms and for burnishing with simultaneous cutting, the selection of conditions should be made on the basis of preliminary tests [3-10, 14-16]. Fig. 1 presents the schema of turning and burnishing rolling - pressuring process.

a)

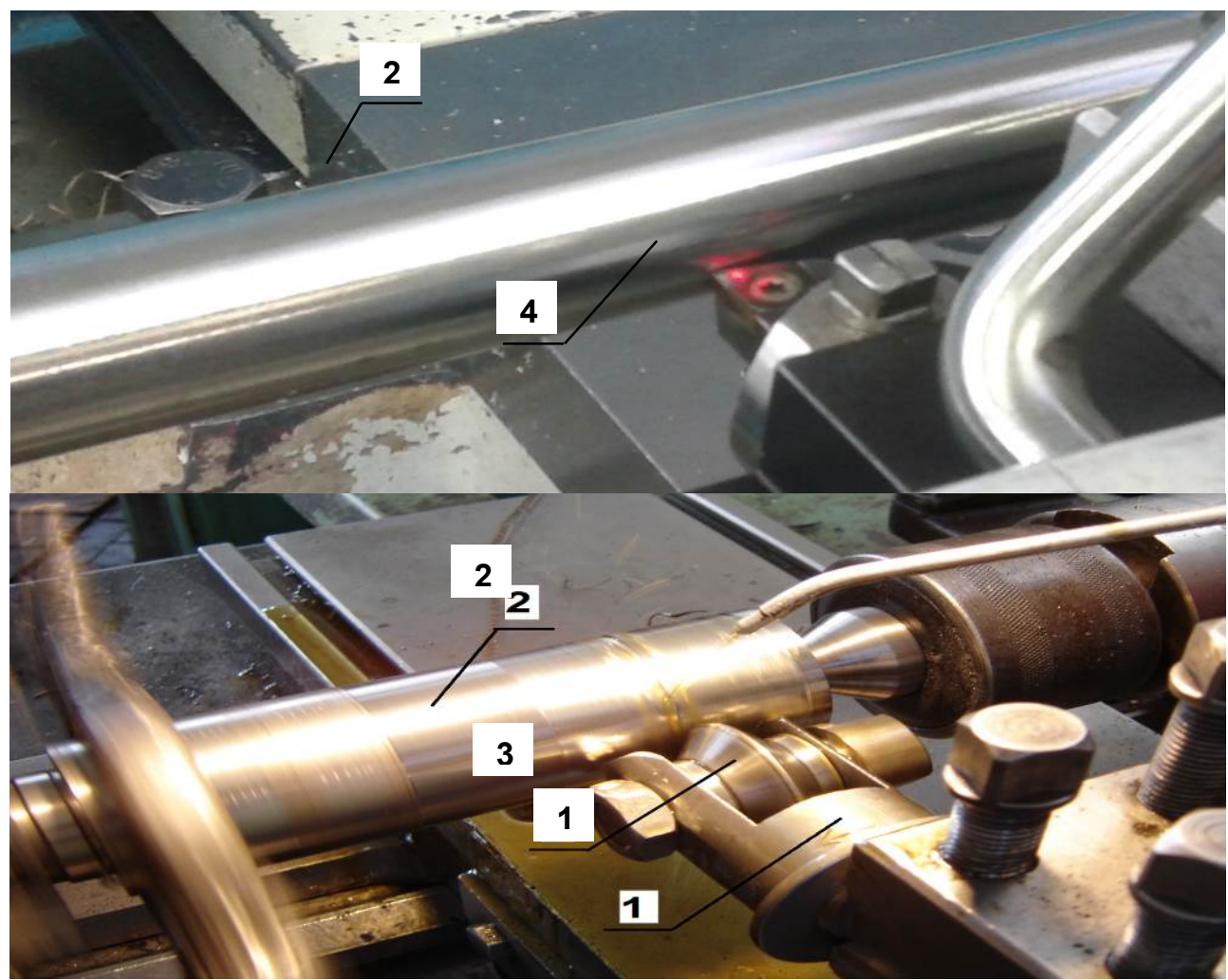

Fig. 1. The schema of machining process: (a) turning and (b) burnishing where: 1 - burnisher roller, 2 -outer cylindrical surfaces, 3 - disk burnishing tool, 4 - turning insert

The technological process resulting in low surface roughness should be realized with application of as much pressure as possible on the surface of the treated element, while the speed of the burnishing and the feed rate should be low. In contrast, burnishing, which is intended to increase the strength properties of the surface layer of the machine parts, inter alia by increasing the hardness, should be characterized by the use of high shear force for low feed rate and burnishing speed. The value of the clamping force should be optimal for each type of burnishing treatment. Too high a value can lead to peeling, which is accompanied by rapid increase in roughness. On the other hand, it is to low value relative to the optimum strength will not provide sufficiently low roughness, because it will not completely deform the remaining inequalities after previous treatments $[3,8]$. Too much clamping pressure of the burnish can adversely affect the quality of the treated surface due to the possibility of appearance of surface defects and the 
presence of stress corrosion $[8,11,13]$. Corrosion resistance of burnished elements depends on the degree of deformation and surface smoothing. It is therefore important for correctly determining the technological parameters of the burn treatment depending on whether it is the smoothness or reinforcement treating. After initial preliminary experiments, of burnishing of the two-phase stainless steel, have been determined that a significant effect on the hardness of the top layer and the roughness of the outer cylindrical surfaces, have the machining parameters (speed, feed rate and depth of burnishing).

\section{The experimental investigations of processing}

In the work were made a series of tests which aimed was modification of the mechanical properties of the surface of the stainless steel, chosen are presented in the article. The experimental investigations were made for samples from the two-phase stainless steel (Fig. 2), with the chemical composition are given in Tab. 1, was analysed using an optical emission spectrometry by Solaris CCD Plus. The ferritic - austenitic steel called duplex is subjected of many material and technological studies, it is characterized with higher tensile strength and better resistance to stress corrosion in comparison to austenitic and ferritic - austenitic steels [4, 12, 13, 17-19].

Barrel outer surfaces were prepared for the burnishing process by machining on a universal lathe CDS 500x1000. The technological turning parameters of machining process were selected on the basis of own research and literature review [17, 20,21]. The following parameters were used: feed rate $f=0.2 \mathrm{~mm} / \mathrm{rev}$, depth of cut $a_{p}=0.5 \mathrm{~mm}$, rotational speed $n=850 \mathrm{rpm}$, cutting speed $v_{c}$ $=70 \mathrm{~m} / \mathrm{min}$. During the process there was no cooling used, dry work was done. Longitudinal turning was made using lathe equipped with CCMT 09T304-UM inserts carbide tipped 2025 with coating $\mathrm{CVD} \mathrm{Ti}(\mathrm{C}, \mathrm{N}) / \mathrm{Al}_{2} \mathrm{O}_{3} / \mathrm{TiN}[21]$.

The burnishing with rigid pressing was realized using a burnisher roller (BR-01) on a universal lathe CDS 500x1000 by exerting a holdfast force on the slider for longitudinal feed rate. The burnisher roller (BR-01) had a burnishing element in the form of a disc with a diameter of $\phi 50 \mathrm{~mm}$ and a rounding radius of a working part of $3 \mathrm{~mm}$ with a hardness of $66 \mathrm{HRC}$. The following technological parameters were used during the burnishing treatment: feed rate $f_{n}=0.1-1.2 \mathrm{~mm} / \mathrm{rev}$; depth of burnishing $a_{n}=0.5-1.0 \mathrm{~mm}$; rotational speed $n=500-1700 \mathrm{rpm}$, burnishing speed $v_{n}=$ $50-140 \mathrm{~m} / \mathrm{min}$, number of machining passes $i=2$. To the process, the machine oil was used for lubrication and cooling.

Tab. 1. The chemical composition of duplex stainless steel GX2CrNiMoCuN25-6-3-3

\begin{tabular}{cccccccccc}
\hline $\mathrm{C}$ & $\mathrm{Cr}$ & $\mathrm{Ni}$ & $\mathrm{Mo}$ & $\mathrm{Cu}$ & $\mathrm{Mn}$ & $\mathrm{Si}$ & $\mathrm{S}$ & $\mathrm{P}$ & $\mathrm{N}$ \\
{$[\%]$} & {$[\%]$} & {$[\%]$} & {$[\%]$} & {$[\%]$} & {$[\%]$} & {$[\%]$} & {$[\%]$} & {$[\%]$} & {$[\%]$} \\
\hline 0.025 & 25.16 & 6.14 & 3.19 & 2.95 & 0.95 & 0.91 & 0.020 & 0.008 & 0.25 \\
\hline
\end{tabular}

The measurements were performed to the principles contained in ISO standards, a number of parameters of surface roughness after burnishing were determined; among other things, parameters were defined associated with the material ratio curve. Before measuring, the sample surfaces were cleaned and degreased. Then was measured profile roughness using a profilometer Hommel Tester T1000. The measurements were made with the assumed measurement section lengths of $4.8 \mathrm{~mm}$ and $0.8 \mathrm{~mm}$ for the elementary section. After measurements of the arithmetical mean deviation of the roughness profile after burnishing were performed, that index of surface roughness reduction $[3,7,13]$ was determined. The arithmetical mean deviation before burnishing of the value was equal to $3.03 \mu \mathrm{m}$. The hardness was measured with the use of Microhardness Tester model FM800 type D by norm ISO/DIS 6507-2 (ASTM E-384). The load of $980.7 \mathrm{mN}$ (100 gf) was applied for 10 seconds at the temperature $26^{\circ} \mathrm{C}$. To assess the effect of the technological parameters on 
microhardness on the surface layer, the degree of relative strain hardening $\left(S_{u}\right)[3,7]$, where before burnishing $392 H V 0.1$ was determined.

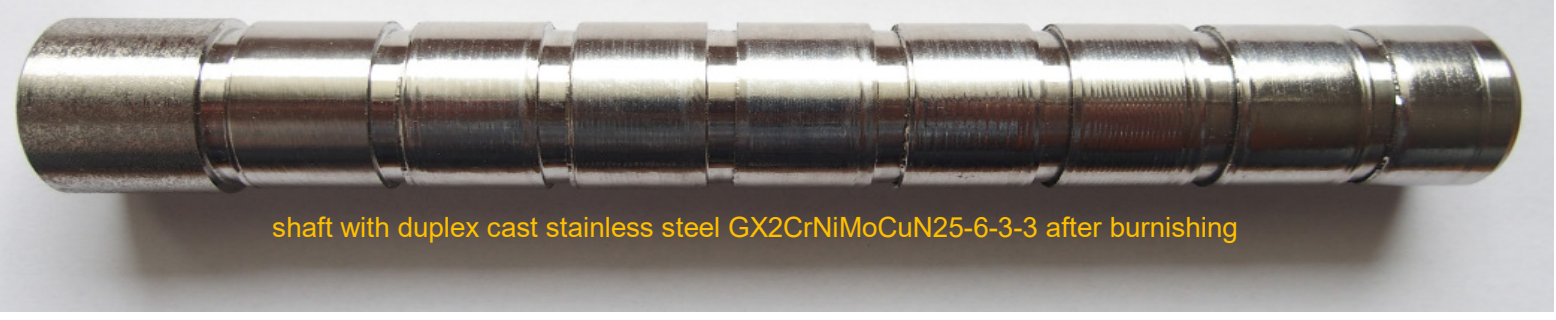

Fig. 2. The view of the sample duplex cast stainless steel series GX2CrNiMoCuN25-6-3-3 after burnishing process

\section{The results of experimental study}

Presented results confirm the theoretical assumptions that the technology of duplex cast stainless steel burnishing not only increases the surface layer properties but also the lifetime of the whole element. The experimental study by application of the burnishing rolling - pressuring process were made in the Laboratory of Production Engineering at the Gdynia Maritime University. The following parameters of burnishing were determined at constant burnishing speed $v_{n}=70 \mathrm{~m} / \mathrm{min}$ and variable feeds $f_{n}=0.1-1.2 \mathrm{~mm} / \mathrm{rev}$ (Tab. 2) and constant feed rate $f_{n}=0.2 \mathrm{~mm} / \mathrm{rev}$. Variable burnishing speed $v_{n}=50-140 \mathrm{~m} / \mathrm{min}$ (Tab. 3) using depth of burnishing of $a_{n}=0.5 \div 1.0 \mathrm{~mm}$ and number of machining passes $i=2$.

Tab. 2. The example of measurements of the parameter of surface roughness and microhardness for the shaft after burnishing for the speed $v_{n}=70 \mathrm{~m} / \mathrm{min}$ for different values of feed rate $f_{n}$ and depth of burnishing $a_{n}$

\begin{tabular}{ccccccccc}
\hline $\begin{array}{c}\mathrm{f}_{\mathrm{n}} \\
{[\mathrm{mm} / \mathrm{rev}]}\end{array}$ & $\begin{array}{c}\mathrm{a}_{\mathrm{n}} \\
{[\mathrm{mm}]}\end{array}$ & HV0.1 & $\begin{array}{c}\mathrm{S}_{\mathrm{u}} \\
{[\%]}\end{array}$ & $\begin{array}{c}\mathrm{Rpk} \\
{[\mu \mathrm{m}]}\end{array}$ & $\begin{array}{c}\mathrm{Rk} \\
{[\mu \mathrm{m}]}\end{array}$ & $\begin{array}{c}\mathrm{Rvk} \\
{[\mu \mathrm{m}]}\end{array}$ & $\begin{array}{c}\mathrm{Ra} \\
{[\mu \mathrm{m}]}\end{array}$ & $\begin{array}{c}\mathrm{K}_{\mathrm{Ra}} \\
{[-]}\end{array}$ \\
\hline 0.1 & 1.0 & 488 & 24.5 & 0.46 & 1.23 & 1.00 & 0.40 & 7.4 \\
0.2 & 1.0 & 489 & 24.7 & 0.60 & 1.13 & 0.76 & 0.37 & 8.1 \\
0.6 & 1.0 & 480 & 22.4 & 2.40 & 7.75 & 1.87 & 2.13 & 1.4 \\
1.2 & 1.0 & 447 & 14.1 & 2.84 & 8.53 & 1.54 & 2.34 & 1.3 \\
0.1 & 0.5 & 478 & 21.9 & 0.41 & 1.62 & 0.93 & 0.44 & 6.9 \\
0.2 & 0.5 & 477 & 21.7 & 0.25 & 1.28 & 1.48 & 0.47 & 6.6 \\
0.6 & 0.5 & 469 & 19.6 & 1.18 & 5.21 & 1.54 & 1.49 & 2.1 \\
1.2 & 0.5 & 445 & 13.5 & 1.56 & 5.06 & 1.50 & 1.52 & 1.9 \\
\hline
\end{tabular}

Tab. 3. The example of measurements of the parameter of surface roughness and microhardness for the shaft after burnishing for the feed rate $f_{n}=0.2 \mathrm{~mm} / \mathrm{rev}$ for different values speed $v_{n}$ of and depth of burnishing $a_{n}$

\begin{tabular}{ccccccccc}
\hline $\begin{array}{c}\mathrm{v}_{\mathrm{n}} \\
{[\mathrm{m} / \mathrm{min}]}\end{array}$ & $\begin{array}{c}\mathrm{a}_{\mathrm{n}} \\
{[\mathrm{mm}]}\end{array}$ & HV0.1 & $\begin{array}{c}\mathrm{S}_{\mathrm{u}} \\
{[\%]}\end{array}$ & $\begin{array}{c}\mathrm{Rpk} \\
{[\mu \mathrm{m}]}\end{array}$ & $\begin{array}{c}\mathrm{Rk} \\
{[\mu \mathrm{m}]}\end{array}$ & $\begin{array}{c}\mathrm{Rvk} \\
{[\mu \mathrm{m}]}\end{array}$ & $\begin{array}{c}\mathrm{Ra} \\
{[\mu \mathrm{m}]}\end{array}$ & $\begin{array}{c}\mathrm{K}_{\mathrm{Ra}} \\
{[-]}\end{array}$ \\
\hline 140 & 1.0 & 440 & 12.2 & 0.29 & 1.74 & 1.17 & 0.51 & 5.9 \\
100 & 1.0 & 471 & 20.2 & 0.87 & 1.03 & 0.97 & 0.41 & 7.4 \\
70 & 1.0 & 489 & 24.7 & 0.60 & 1.13 & 0.76 & 0.37 & 8.1 \\
50 & 1.0 & 488 & 24.5 & 0.83 & 0.97 & 1.13 & 0.43 & 7.0 \\
140 & 0.5 & 453 & 15.6 & 0.58 & 1.47 & 0.98 & 0.53 & 5.7 \\
100 & 0.5 & 477 & 21.7 & 0.70 & 1.40 & 0.97 & 0.45 & 6.7 \\
70 & 0.5 & 486 & 23.9 & 0.25 & 1.28 & 1.48 & 0.47 & 6.8 \\
50 & 0.5 & 485 & 23.7 & 0.67 & 1.67 & 0.96 & 0.49 & 6.2 \\
\hline
\end{tabular}


After experimental tests, the correlation between the burnishing conditions and the surface roughness reduction (Fig. 3) and the degree of relative strain hardening (Fig. 4) were determined at the set parameters of the static pressure rolling burnishing of the outer cylindrical surface. After burnishing, the relationship between the burnishing conditions and the surface roughness and the degree of relative strain hardening was developed. According to the data shown in Fig. 3 can be stated that the value of the surface roughness reduction $\left(K_{R a}\right)$ decreases as the feed rate of the burnishing increases. The smallest values of the arithmetic mean of the ordinates of surface roughness, after burnishing and thus the maximum values of the surface roughness decrease for low values of feed rates.

On the base of the analysis of results in Fig. 4, it can be concluded that, as the burn rate increases, the degree $\left(S_{u}\right)$ is lower. On the other hand, for the smaller feed rate values and for the larger values of the depth of the burnishing, the relative strength of the surface layer is maximized.
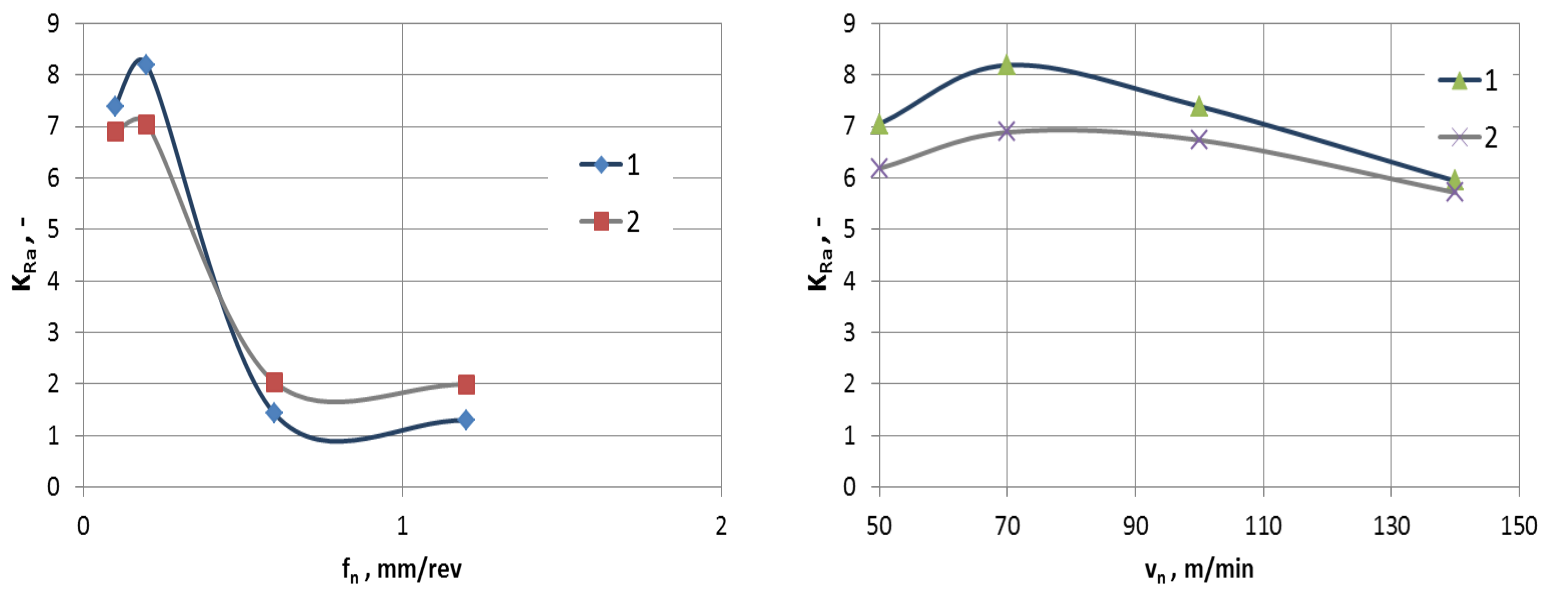

Fig. 3. The effect of the feed rate $f_{n}$ and speed $v_{n}$ on index of surface roughness reduction $\left(K_{R a}\right)$ after burnishing for depth: $1-a_{n}=1.0 \mathrm{~mm}$ and $2-a_{n}=0.5 \mathrm{~mm}$
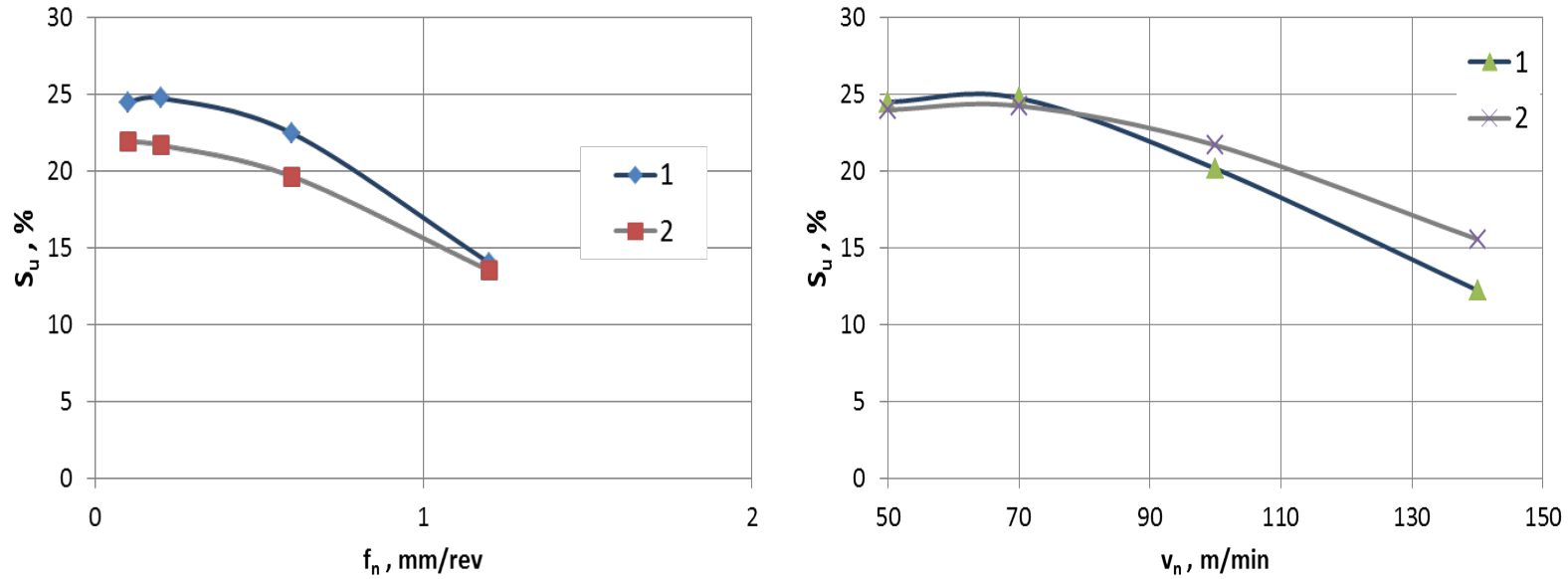

Fig. 4. The influence of the feed rate $f_{n}$ and speed $v_{n}$ on degree of relative strain hardening $\left(S_{u}\right)$ after burnishing for depth: $1-a_{n}=1.0 \mathrm{~mm}$ and $2-a_{n}=0.5 \mathrm{~mm}$

Figure 3 shows the effect of the burn rate on the surface roughness reduction index. It can be seen that increasing the burnishing speed values initially results in an increase in the value of the $\mathrm{K}_{\mathrm{Ra}}$ index and thus decreasing the roughness of the surface. The maximum values for this indicator are for a burnishing speed of $v_{n}=70 \mathrm{~m} / \mathrm{min}$. Increasing of the velocity of burnishing results the surface roughness deterioration. 
According to data shown in Fig. 4 can be stated that with the increase in velocity, the degree of relative strain hardening $\left(S_{u}\right)$ is lower. In addition, for the lower speed values and higher values of the depth of the burnishing, the relative strength of the surface layer gets the maximum value.

The analysis of data and dependencies presented in Fig. 3 and 4, it can be stated that to achieve a reduction in surface roughness and to increase the hardness of the surface layer after the treatment of the GX2CrNiMoCuN25-6-3-3, for specified technological parameters, should be use $v_{n}=70 \mathrm{~m} / \mathrm{min}$, feed rate $f_{n}=0.2 \mathrm{~mm} / \mathrm{rev}$ and depth of burnishing $a_{n}=1.0 \mathrm{~mm}$.

The Fig. 5 and 6 showed the parameters and graph for material ratio curve surface roughness before and after burnishing process of the duplex cast stainless steel. On the basis of analysis of experimental results after burnishing it can be determined, that the roughness profile parameters and parameter values of the material ratio curve reached the lowest values.

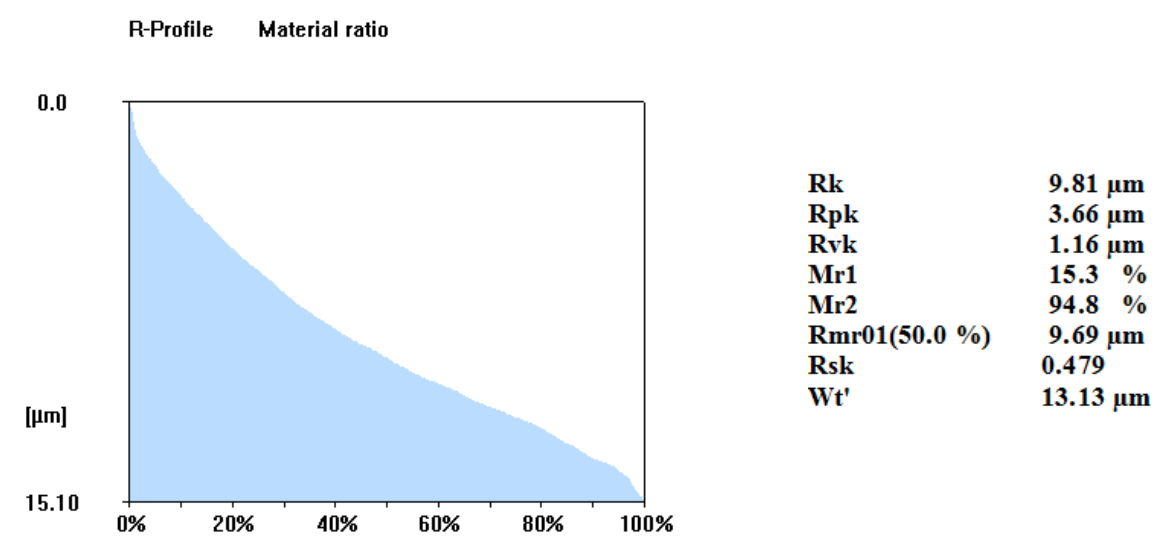

Fig. 5. The material ratio curve surface roughness and the parameters after turning by CCMT 09T304-UM 2025 carbide tipped inserts $(R a=3.03 \mu \mathrm{m})$

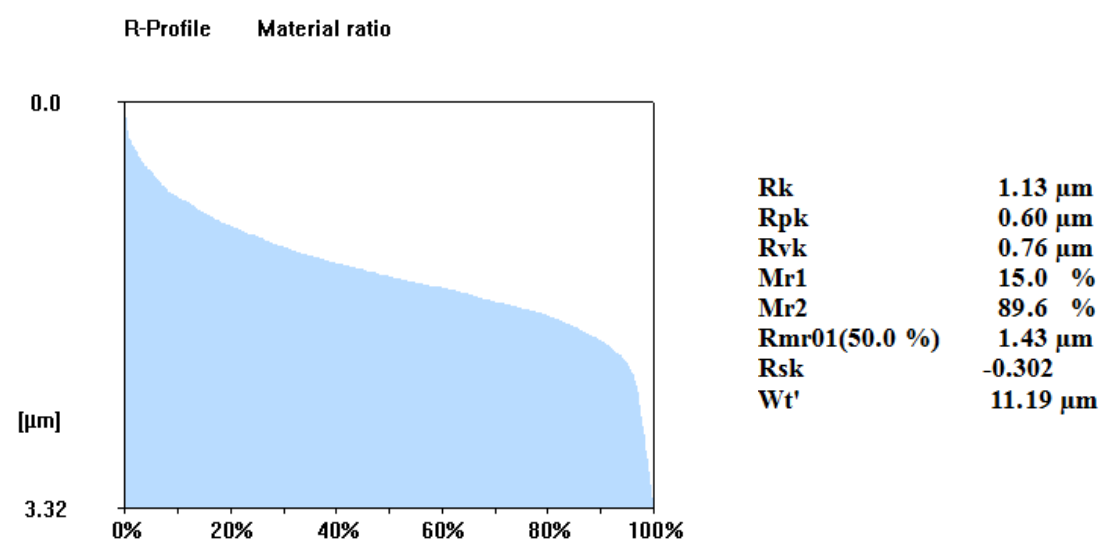

Fig. 6. The material ratio curve surface roughness and the parameters after burnishing by burnisher roller (BR-01) of the GX2CrNiMoCuN25-6-3-3 duplex cast stainless steel ( $R a=0.37 \mu \mathrm{m})$

\section{Summary and conclusions}

After the experimental investigations of the burnishing, the effect the burnishing speed and feed rate on the index of surface roughness reduction and the degree of relative strain hardening were determined. After the analysis of test results, it was determined that along with the increase in feed rate and burnishing speed, the degree of relative strengthening surface values of the layer and the index of surface roughness reduction decrease.

Afterward the experimental research of the burnishing rolling - pressuring process of the GX2CrNiMoCuN25-6-3-3 duplex cast stainless steel, it was stated that: 
To the hardness and the surface roughness of the of the outer cylindrical surfaces have influence the machining parameters (burnishing speed, feed rate and depth of burnishing);

There is a relationship between the feed rate, the speed of burnishing, the index of surface roughness reduction and the degree of relative strengthening by cold working;

With the feed rate and burnishing speed increase, decreases the relative strength of the surface layer and the surface roughness factor.

The maximum values of the index of surface roughness reduction $K_{R a}=8.1$ and the degree of relative strain hardening $S_{u}=24.7 \%$ were obtained for $v_{n}=70 \mathrm{~m} / \mathrm{min}, f_{n}=0.2 \mathrm{~mm} / \mathrm{rev}$ and $a_{n}=$ $1 \mathrm{~mm}$.

The burnishing process of the duplex cast stainless steel to simultaneously achieve smoothing and reinforcing purposes should be carried out at the recommended parameters: feed rate $f_{n}=0.2$ $\mathrm{mm} / \mathrm{rev}$; depth of burnishing $a_{n}=1 \mathrm{~mm}$, burnishing speed $v_{n}=70 \mathrm{~m} / \mathrm{min}$ and number of machining passes $i=2$.

By using lower feed rates and lower burnishing rates at higher infraction rates for the specified test range, the maximum relative strength of the surface layer as well as the maximum surface roughness index values can be obtained.

\section{References}

[1] Brinksmeier, E., Garbrecht, M., Meyer, D., Cold surface hardening, CIRP Annals Manufacturing Technology, Vol. 57, 541-544, 2008.

[2] Czechowski, K., Polowski, W., Wszołek, J., The burnishing rolling as a method of finishing, Design and Engineering Constructions, No. 6, pp. 22-31, 2009.

[3] Dyl, T. C., The burnishing process of the stainless steel in aspect of the reduction roughness and surface hardening, Journal of KONES, Vol. 24, No. 3, pp. 63-70 2017.

[4] Dyl, T., Rydz, D., Stradomski, G., The burnishing process of two-phase cast steel in the aspect of reducing roughness and increase of hardness, Scientific Journal of Gdynia Maritime University, 100, pp. 76-86, 2017.

[5] Dyl, T., Stradomski, G., Rydz, D., Effect of the reduction ratio on the state strain of the steel tubes after burnishing broaching process, 23rd International Conference on Metallurgy and Materials, Brno Czech Republic EU, pp. 335-340, 2014.

[6] Rydz, D., Krakowiak, M., Bajor, T., Stradomski, G., The Analysis of the Impact Relative Rolling Reduction at the Area Connector Bimetallic Plate After the Rolling Process, Solid State Phenomena, Vol. 199, pp. 514-517, 2013.

[7] Kukiełka, L., Theoretical and experimental basis of surface burnishing with electro-contact heating, WU WSI, Koszalin 1994.

[8] Przybylski, W., Technology of burnishing process, WNT, Warszawa 1987.

[9] Labuda, W., Starosta, R., Dyl, T., Estimation of the influence of burnishing parameters on steel X5CrNi18-10 surface layers strengthening and roughness changes, Journal of KONES, Vol. 15, No. 3, pp. 259-267, 2008.

[10] Korzyński, M., Burnishing slide, WNT, Warszawa 2007.

[11] Dyl, T., Starosta, R., Effect of the Ceramic Dispersion in the Nickel Matrix Composite Coatings on Corrosion Properties after Plastic Working, Solid State Phenomena, Vol. 183, pp. 43-48, 2012.

[12] Konefał, K., Korzyński, M., Byczkowska, Z., Korzyńska, K., Improved corrosion resistance of stainless steel X6CrNiMoTi17-12-2 by slide diamond burnishing, Journal of Materials Processing Technology, Vol. 213, Iss. 11, 1997-2004, 2013.

[13] Labanowski, J., Ossowska, A., Influence of burnishing on stress corrosion cracking susceptibility of duplex steel, Journal of Achievements in Materials and Manufacturing Engineering, Vol. 19, Issue. 1, pp. 46-52, 2006. 
[14] Dyl, T. C., Analysis of the burnishing process testing by the methods - BRP, Journal of KONES, Vol. 23, No. 3, pp. 121-126, 2016.

[15] Tubielewicz, K., Technology and tooling in surface treatment, PCz, Częstochowa 1996.

[16] Kukiełka, L., Szczesniak, M., Patyk, R., Kułakowska, A., Kukiełka, K., Patyk, S., Gotowała, K., Kozak D., Analysis of the states of deformation and stress in the surface layer of the product after the burnishing cold rolling operation, Materials Science Forum, Vol. 862, pp. 278-287, 2016.

[17] Królczyk, G. M., Niesłony, P., Legutko, S., Determination of tool life and research wear during duplex stainless steel turning, Archives of Civil and Mechanical Engineering, Vol. 15, No. 2, pp. 347-354, 2015.

[18] Stradomski, G., The Analysis of AISI A3 Type Ferritic - Austenitic Cast Steel Crystallization Mechanism, Archives of Foundry Engineering, Vol. 17, Issue 3, pp. 229-233, 2017.

[19] Nowacki, J., Duplex steel and its weldability, WNT, Warszawa 2009.

[20] Dyl, T. C., The influence of the geometry of the cutting edge and machining parameters of duplex cast steel after turning, Journal of KONES, Vol. 25, No. 4, pp. 75-82, 2018.

[21] Tools for metal cutting, Turning inserts, Catalog CoroTurn ${ }^{\circledR}$, Sandvik Coromant, 2019. 